\title{
Infraestrutura verde: um novo olhar para o desenho urbano ${ }^{1}$
}

Green infrastructure: a new look at urban design

\author{
Infraestructura verde: una nueva mirada al diseño urbano
}

\author{
Jeane Aparecida Rombi de Godoy Rosin \\ Pós-doutoranda pelo PPGARQ-UNESP. \\ Doutorado em Arquitetura e Urbanismo pela UPM. \\ jeanerosin@terra.com.br
}

\footnotetext{
${ }^{1}$ Texto extraído do livro “Estudos Urbanos: uma abordagem interdisciplinar da cidade contemporânea”. 1. ed. Tupã, 2015.
} 


\section{RESUMO}

A questão abordada nesse artigo tem por propósito, realizar uma reflexão sobre a importância da incorporação dos princípios ambientais que orientam o novo urbanismo na contemporaneidade, ao possibilitar uma nova visão do processo de planejamento e suas interfaces com o desenho urbano. Ainda que esse enfoque possibilite um novo olhar sobre a cidade, ao considerar as interfaces que permeiam o meio ambiente e a sociedade em suas especificidades e interações, sua maior contribuição está em criar novos caminhos de adaptação e adequação, visando à obtenção de soluções inteligentes as complexas demandas apresentadas pela cidade contemporânea. Nesse sentido, os processos de planejamento ecológico, ao trazerem em seu bojo novos princípios, por meio da integração dos elementos naturais as áreas urbanas, conformam estratégias fundamentais para a mitigação das grandes questões ambientais oriundas do processo de produção das cidades, dialogando com os diversos campos do saber em busca da reinvenção da cidade, para muitos especialistas uma atividade inacabada.

Palavras-Chave: Meio Ambiente. Planejamento. Infraestrutura verde.

\section{ABSTRACT}

Die vraag in hierdie opsommende artikel aangespreek het deur doel, voer 'n refleksie op die belangrikheid van die inlywing van omgewings beginsels wat lei die nuwe stadskultuur in hedendaagse tye, deur ' $n$ nuwe visie van die beplanningsproses en sy koppelvlakke met die Stedelike ontwerp. Hoewel hierdie benadering laat ' $n$ nuwe perspektief op die Stad, by die oorweging van koppelvlakke wat deurtrek van die omgewing en samelewing in sy specificities en interaksies, jou grootste bydrae is om nuwe maniere van aanpassing en fiksheid, mik op die verkryging oplossings skep Intelligente komplekse eise wat deur die hedendaagse Stad aangebied word. In hierdie sin, die prosesse van ekologiese beplanning te bring in jou Bult nuwe beginsels, deur integrasie van natuurlike elemente stedelike gebiede, oorreed om die fundamentele versagtende strategieë belangrike omgewingskwessies van die produksie proses die stede, in dialoog met die verskillende velde van kennis herdenk die reinvention van die Stad, vir baie kenners 'n onvoltooide aktiwiteit.

Keywords: Environment. Planning. Green infrastructure.

\section{RESUMEN}

La cuestión abordada en este artículo tiene por propósito, realizar una reflexión sobre la importancia de la incorporación de los principios ambientales que orientan el nuevo urbanismo en la contemporaneidad, al posibilitar una nueva visión del proceso de planificación y sus interfaces con el diseño urbano. Aunque este enfoque posibilite una nueva mirada sobre la ciudad, al considerar las interfaces que permean el medio ambiente y la sociedad en sus especificidades e interacciones, su mayor contribución está en crear nuevos caminos de adaptación y adecuación, buscando la obtención de soluciones inteligentes complejas demandas presentadas por la ciudad contemporánea. En este sentido, los procesos de planificación ecológica, al traer en su seno nuevos principios, a través de la integración de los elementos naturales en las áreas urbanas, conforman estrategias fundamentales para la mitigación de las grandes cuestiones ambientales oriundas del proceso de producción de las ciudades, dialogando con los diversos los campos del saber en busca de la reinvención de la ciudad, para muchos expertos una actividad inacabada.

Palabras clave: Medio Ambiente. Planificación. Infraestructura verde. 


\section{INTRODUÇÃO}

Na contemporaneidade, uma parte significativa das sociedades se defronta com as tendências inquietantes que tendem a intensificar o caos urbano, resultante do padrão arcaico de uso e ocupação territorial adotado ao longo da era industrial e que se manifesta até os dias atuais contextos onde são identificados cenários com concentração de poder e riquezas, as quais se manifestam em enormes disparidades sociais, econômicas e ambientais, gerando conflitos de toda ordem.

Ao longo do século $\mathrm{XX}$, o processo de urbanização no país passou por uma transformação conduzida pela economia de agro exportação à economia urbano-industrial, alterando a distribuição da população em seu território, ou seja, o Brasil tornou-se urbano.

Entretanto, o modelo de urbanização adotado possibilitou o agravamento dos processos de diferenciação sócio espacial, explicitados no processo de informalidade urbana. Embora tais aspectos apresentem fisionomias diversificadas, alterando-se em conformidade com os aspectos geográficos, culturais de uma determinada localidade, eles mostram a estrutura econômica e social intensamente desigual e injusta. No que se refere às especificidades envoltas às questões ambientais, o padrão de desenvolvimento econômico implantado nas cidades foi drástico ao impactar severamente os recursos de maior relevância para a vida nas cidades - os recursos naturais, notadamente, com a ocupação indiscriminada de áreas de mananciais e encostas - ambientalmente vulneráveis. Nesse contexto, a literatura mostra que, há um consenso entre os especialistas, sobretudo, das ciências sociais em afirmar que esse padrão de urbanização deu origem aos fenômenos de fragmentação urbana e que para outros são denominados de segregação. 0 amplo quadro de efeitos produzidos por esses fenômenos independe de sua nomenclatura frente à gravidade dos cenários que emergem em diversas dimensões. O que leva a perceber que a questão urbana vem ao longo de décadas atravessando as maiores adversidades frente à urgência de seu reconhecimento, seja por meio do adequado equacionamento de suas demandas na edição de novas legislações, tanto quanto, na implementação de políticas públicas visando suprir as deficiências habitacionais, de infraestrutura física e social - como questões estratégicas ao desenvolvimento do país. Dessa forma, o contexto apresentado ao explicitarem as graves questões que afetam uma vivência saudável em diversas cidades do país, procuram evidenciar a urgência de intervenções governamentais que contemplem novos paradigmas de planejamento e gestão das cidades, essencialmente, no que se refere ao direito à cidade - em conformidade com os princípios constitucionais, sobretudo, àqueles que almejam a implementação da sustentabilidade urbana. Assim a questão abordada nesse artigo tem por propósito, realizar uma reflexão sobre a importância da incorporação dos princípios ambientais que orientam o novo urbanismo na contemporaneidade, ao possibilitar uma nova visão do processo de planejamento e suas interfaces com o desenho urbano. Pensar a cidade, a partir de metodologias projetuais, com a conjugação estratégica de elementos da natureza é de fato uma possibilidade e sobretudo uma composição ímpar de ideias, onde a paisagem explicita um ecossistema dinâmico, nos quais os 
fatores biofísicos e humanos orientam o processo de tomada de decisões intrínsecas ao planejamento e ao desenho urbano (MACHARG, 2000). Essa visão ampliada, foi denominada por MachHarg, por planejamento ecológico, onde o autor enfatiza sua importância para a melhoria da qualidade de vida. Para Hough $(1998$, p.5) a submissão presente nos sistemas vivos, permite a interconexão da evolução dos processos físicos e vitais da terra em incessante transformação, ao contribuírem para a recuperação dos materiais vivos e não vivos, são os "elementos que propiciam a autossuficiência da biosfera, que permitem a vida na terra e que dão lugar à paisagem física. Constituem os elementos determinantes que dão forma a todas as atividades sobre a terra".

Ainda que esse enfoque possibilite um novo olhar sobre a cidade, ao considerar as interfaces que permeiam o meio ambiente e a sociedade em suas especificidades e interações, sua maior contribuição está em criar novos caminhos de adaptação e adequação, visando à obtenção de soluções inteligentes as complexas demandas apresentadas pela cidade contemporânea. Nesse sentido, os processos de planejamento ecológico, ao trazerem em seu bojo novos princípios, por meio da integração dos elementos naturais as áreas urbanas, conformam estratégias fundamentais para a mitigação das grandes questões ambientais oriundas do processo de produção das cidades, dialogando com os diversos campos do saber em busca da reinvenção da cidade, para muitos especialistas uma atividade inacabada.

\section{SUSTENTABILIDADE PARA O PROJETO URBANO: POSSIBILIDADES E DESAFIOS}

Um exercício de observação por meio de uma percepção objetiva, realizado por olhares especializados sobre as cidades contemporâneas, certamente levará a compreender o quanto tem se tornado urgente à incorporação dos elementos naturais em áreas urbanizadas, não somente pelos recursos estéticos que podem atenuar as agruras do cotidiano, ao trazer um pouco de poesia, cor e musicalidade para os cenários pesados e cansados que conformam as atuais cidades, mas em razão da importância da conservação e contribuição de seus elementos para o equilíbrio do ecossistema urbano. Ideia que encontra fundamento na visão demostrada por MacHarg (2000), ao afirmar que as questões decorrentes da relação homem e natureza, não podem ser equacionadas ao empregá-las enquanto elemento estético, visando o deleite proporcionado pela beleza de suas paisagens, como também, com a função de amenizar os desconfortantes ambientes presentes em espaços urbanos. Com base nesses apontamentos Ribeiro $(2010$, p. 26$)$ alerta para a necessidade de se "adotar uma postura em que ela figure como base estratégica. Sobretudo, é preciso investigar e descobrir suas particularidades e sutilezas como fonte e significado".

Longe de se constituírem em um prelúdio para uma nova era, talvez seja essa, um caminho para as metas e diretrizes que visam alcançar à civilidade, vitalidade e a tão desejada urbanidade, proclamadas recentemente em planos, programas e em uma proporção maior em pesquisas, considerando os valores irradiados nos diversos campos do saber desde a declaração da Carta da Terra. Para Ribeiro (2010, p. 26) essa consciência nasce do 
entendimento de que a natureza é em sua essência um conjunto de interações sujeitas às suas leis, com valores e oportunidades disponíveis ao homem, porém, com restrições a serem cumpridas.

Hough $(1998$, p. 5) complementa com ênfase a submissão presente nos sistemas vivos, que permitem interconexão da evolução dos processos físicos e vitais da terra em incessante transformação, onde se dá a recuperação dos materiais vivos e não vivos. Para este autor, estes são "os elementos que propiciam a autossuficiência da biosfera, ao ensejar a vida na terra e que dão lugar à paisagem física. Constituem os elementos determinantes que dão forma a todas as atividades sobre a terra". É importante ressaltar outro aspecto levantado com base em diversos dados apresentados por pesquisas recentes, as quais apontam um significativo aumento demográfico e econômico, que em um primeiro momento pode gerar reações inusitadas quanto ao futuro das cidades, entretanto, MacHarg $(2000$, p. 23) apresenta uma visão bastante ponderada, ao colocar "que o crescimento é inevitável, porém o desenvolvimento não implica destruição". Considera ainda, que há possibilidade de uma adequação e adaptação visando um contexto de equilíbrio, todavia deve ser entendido como resultado do comprometimento de cada sociedade na medida em que "acreditam que o homem e natureza são indivisíveis e que a sobrevivência e a saúde dependem da sua compreensão do ambiente natural e de seus processos" (MACHARG, 2000, p. 26).

Não somente no Brasil como em outras cidades da América Latina, os processos de planejamento voltados à questão urbana, ao produzir planos e programas expressam pouca ou quase nada, atenção as condicionantes ambientais, gerando antagonismos de diversas dimensões. Reconhecer esses fatos, constitui-se no primeiro passo para a revisão de posturas e valores frente à compreensão das interfaces que permeiam a relação homem e natureza, as quais envolvem os aspectos físicos e socioculturais de uma determinada localidade.

Essa percepção da relevância dos componentes que os ambientes naturais podem oferecer para obtenção de soluções inteligentes ao conjugarem os componentes do meio natural ao projeto urbano, ao observar os aspectos relacionados à geologia (formação e composição dos solos), os padrões e técnicas de parcelamento do solo a partir das condições geofísicas, assim como, a massa arbórea, os recursos hídricos em toda sua diversidade contribuem para uma nova visão de pensar e projetar a vida em cidades. Tais preocupações não permitirão o uso indevido ou limitado desses recursos, ao serem destinados apenas ao abastecimento (uso doméstico e industrial), ao lazer e recreação, o que torna necessário a identificação da função específica que cada componente pode desempenhar nos espaços urbanizados, considerando não apenas suas potencialidades, mas suas características quanto a vulnerabilidade, de proteção dos corpos d'água, ou seja, os serviços ambientais as quais desempenham. Muito embora, esses aspectos sejam essenciais para a construção da sustentabilidade, torna-se fundamental ainda, a compreensão que a preservação e a conservação de determinados locais apresentam também para a preservação da vida humana, por meio da purificação do ar, amenização de temperaturas, a dispersão de poluentes, o controle de processos erosivos, além de toda beleza e riqueza da fauna e flora e de solos férteis. Por outro lado, é de extrema 
importância considerar que, a não observância de tais aspectos podem resultar em uma gama de problemas, como a ocorrência eventos ambientais em diversas localidades do país, onde são observados um número crescente de inundações, desmoronamentos de encostas, desertificação do solo, secas por períodos prolongados, elevação da temperatura, que tende a se agravar frente às previsões de alteração do clima. Com esse enfoque, Ribeiro (2010, p. 28) alerta para os atuais quadros urbanos apresentados em diversas localidades, os quais "coloca à prova a sustentabilidade urbana como fruto entre espaço natural e social, centrada na conservação das condições ecológicas, porém adequando-as às comunidades". Com esses propósitos, muitas pesquisas têm sido desenvolvidas a partir dessa nova visão, ao incorporarem dentre outros fatores, "as soluções naturais de investigação, conhecimento, respeito e manutenção de vegetação natural dos cursos d’água" (RIBEIRO, 2010, p. 28). Dentro de suas especificidades, são ações técnicas adequadas em que o mesmo autor as reconhece, "como forma de conter os solos e obter uma drenagem eficiente mais econômica e adequada às intervenções de engenharia e suas obras de arte". Em uma visão proativa, admite-se uma possibilidade ímpar para uma aproximação teórica e prática com vistas a integração e articulação de saberes e vivências diferenciadas em um ambiente fértil permeável a um debate mais abrangente, capaz de definir um plano de prioridades com metas e recomendações dedicadas a reconversão das áreas degradadas em espaços potenciais para áreas urbanizadas em várias regiões brasileiras.

Para Henri Acselrad (2001), a grande questão que envolve a construção da sustentabilidade urbana, a partir da adoção de novos paradigmas, não deve limitar-se as concepções de um urbanismo ecologizado, baseado na projeção de cidades compactas, visando à economia de espaço e energia, do mesmo modo, não se deve fazer uso da sustentabilidade apenas como um atributo simbólico voltado para o marketing das cidades. No momento atual, o que interessa para os possíveis destinos da cidade - seu futuro é pensar um novo modelo de desenvolvimento urbano, que além dos princípios ambientais, seja capaz de conjugar os princípios da democratização dos territórios, no enfrentamento dos processos de segregação socioespacial, ao facultar acesso a serviços urbanos de qualidade, sobretudo, na superação da desigualdade social materializada nas diversidades de exposição aos riscos urbanos (ASCELRAD, 2001 , p. 23). Neste cenário, emergem inúmeras ideias, propostas voltadas a concepção de intervenções urbanas com a finalidade de alcançar espaços sustentáveis, assim torna-se obrigatório o entendimento que os processos que promovem a sustentabilidade, é antes de tudo um fator de desenvolvimento, e não o seu oposto. Podendo dessa forma, conduzir a um processo inteligente de crescimento, elevando a níveis de equidade e justiça social por meio da implementação estratégica de políticas públicas inovadoras.

\section{PLANEJAMENTO URBANO ECOLÓGICO: ALGUMAS QUESTÕES...}

Com base em uma nova visão dedicada ao urbanismo para o século XXI, o planejamento urbano ecológico passa a configurar novas metodologias atreladas aos valores e recursos 
naturais, ecológicos e ambientais como elementos da paisagem, principalmente por constituírem-se em partes integrantes do contexto sociocultural das cidades. Considerado uma ferramenta especializada, por seu caráter interdisciplinar e transdiciplinar, possuiu interfaces com diversos campos do conhecimento, o que torna decisivo para empreender novas abordagens relacionadas ao pensar e intervir em cidades, nos processos que sejam capazes de conjugar o meio físico com a natureza, vencendo posturas arcaicas que pouco tem contribuído para a melhoria do espaço urbano. Diante desses apontamentos, os métodos e procedimentos que integram o processo do desenho urbano, requer a inclusão da dimensão ecológica orientados por valores que permeiam a relação homem e natureza, ao considerarem a espécie humana como parte dos ecossistemas naturais.

Pellegrino (2000) por sua vez, compreende sua relevância ao enfatizar o planejamento urbano ecológico, como concepção de proposições espaciais aptas em promover as mudanças necessárias dos componentes que integram a paisagem a fim de que as intervenções humanas se realizem em concordância com a capacidade de suporte dos ecossistemas. Ribeiro (2010, p.36) ao analisar sua caracterização e propriedades enquanto um sistema de alternativas futuras visando a inclusão dos processos naturais nos espaços urbanizados, compreende o planejamento urbano ecológico como uma "definição criteriosa da acomodação das atividades humanas sobre uma base biofísica de suporte. É a mediação entre as ações do homem e seu território". O mesmo autor, complementa essa ideia ao enfocar, que se trata da materialidade de um processo, assim como de um domínio da prática profissional relacionada à pesquisa da arquitetura da paisagem e do planejamento urbano ecológico, desse modo "por mais adequados que sejam os projetos, eles só se qualificam pela apropriação social, portanto 'a materialidade do projeto se dá no lugar da vivência cotidiana'" (RIBEIRO, 2010).

Nesse contexto, todo o processo decorrente do planejamento urbano ecológico requer uma forma de pensar e atuar em espaços urbanizados, por meio de um plano complementar ao plano urbano oficial, com a finalidade de propor ações potencializadas a serem implementadas dentro do contexto de cada localidade. Com esse enfoque, Ribeiro (2010) deixa evidente que,

\footnotetext{
A postura de pensar e agir sobre a cidade demanda um plano complementar que subsidie o plano urbano. Ao reconhecer que a cidade necessita ser compensada diante dos inúmeros problemas biofísicos e sociais evidentes, apresenta propostas fundamentadas passíveis de serem implementadas a curto prazo, sem desdobramentos nocivos a longo prazo, e que provêem recursos ao desenvolvimento sociocultural e do meio ambiente. Trata-se de um planejamento que adota uma postura ética com relação à natureza e a sociedade (p.37).
}

É indiscutível, que a incorporação de tais valores, passa por um processo de transformação, uma quebra de paradigmas que pode surgir em contextos nos quais determinados segmentos despertam para os limites e vulnerabilidades da lógica do desenvolvimento econômico, onde obrigatoriamente há o reconhecimento da necessidade desse novo paradigma, ao considerar seus fundamentos - pautados por uma nova ética urbana apta em orientar os valores e 
comportamentos para os propósitos da implementação da sustentabilidade ecológica e da equidade social (LEFF, 1999, p. 112 e 113).

Essa condição pressupõe um novo "modus operandi" para trabalhar as questões urbanas, analisando os princípios e práticas que compreende o processo de planejamento urbano tradicional ao possibilitar uma nova compreensão sobre as dinâmicas que compõem o urbano. A partir desse modelo, passam a ser imprescindíveis às restrições ambientais, ecológicas e paisagísticas de uso e ocupação, que em sua essência buscam promover benefícios estéticos, sociais e econômicos preciosos para alcançar patamares satisfatórios ao bem-estar social. Em síntese, o foco primordial a ser considerado, refere-se à condição sine qua non em criar uma nova mentalidade cultural, que permita avanços tanto na concepção de legislações, formulação de políticas públicas e seus produtos imediatos - programas, planos, projetos e sistemas que atuam diretamente no contexto das cidades.

Dentro dos valores e significados estabelecidos, Ribeiro (2010) comenta que "o escopo é reequilibrar o tecido urbano, freando as expansões meramente mercantis e industriais que geram concentrações e vazios urbanísticos, e contribuir para preservar espaços abertos e zonas naturais".

Ao comparar o planejamento urbano ecológico ao planejamento tradicional, verifica-se uma nítida evolução relacionada a dois aspectos - o da escala e o elemento humano, principalmente por ser concebido como ciência que investiga o processo de produção das cidades, sua fragmentação e suas interrelações com o meio natural. Para tanto, Pellegrino (2006) acredita que a fragmentação resulta da ruptura dos ecossistemas naturais, como decorrência do processo de produção das cidades, que incontestavelmente gera o rompimento da conectividade, drástica redução e impermeabilização dos espaços. Nesse sentido, a conectividade pode ser aquela compreendida por Ribeiro (2010), como o esforço realizado em sentido oposto,

\footnotetext{
[...] determinado por espaços físicos bem delimitados, como os corredores verdes, e é definida como a capacidade da paisagem de gerar fluxos entre seus elementos bióticos. É um conceito que integra a capacidade dos processos bióticos, dada por mecanismos internos capazes de absorver e resistir às mudanças, garantindo-lhes flexibilidade e perenidade. Funda-se nos princípios ecológicos próprios dos ecossistemas naturais, quais sejam: mínima intervenção nos espaços da estrutura ecológica de sustentação; equilíbrio entre população e recursos; preservação da diversidade; manutenção sistêmica. (p.37).
}

Das breves reflexões aqui apresentadas, entende-se que o planejamento urbano ecológico não é um sistema rígido, resultante de formulas fixas que encara a cidade por meio de uma visão genérica, de modo contrário, adota por fundamento, os princípios ecológicos que interconectam modelos e métodos em procedimentos dinâmicos. No âmbito da questão, a ecologia da paisagem, dispõe de um sistema de princípios voltados ao planejamento e desenho da paisagem urbana e regional, oferecendo mecanismos eficientes a serem empregados na coleta de dados, análise, diagnósticos e interpretação de dados. Para os especialistas que 
trabalham com esta questão e que intencionam desenvolver propostas inteligentes, dispor de recursos que permitam a espacialização em todo o processo de projetação, possibilita a concepção de uma série de propostas projetuais, além de ampliar a interface não apenas entre as áreas afins, como também, favorecer o diálogo entre os tomadores de decisão, como etapa fundamental do processo.

Nessa perspectiva, a busca por proposta que tenha por fim a concepção de ambientes harmoniosos, que possam contribuir para construção da sustentabilidade em áreas urbanas, a técnica primeira consiste em identificar no contexto de cada local, os mosaicos de paisagens, as configurações biofísicas de suporte com a preocupação de adaptá-las aos princípios de ocupação e conservação, pois o modo como esses elementos serão empregados no desenho urbano, para muito além de refletir a qualidade projetual, será uma referência da cultura de seus habitantes.

O planejamento urbano ecológico, ao considerar as condicionantes do ambiente natural, propõe um novo modelo de ocupação flexível às condicionantes do território em observância aos princípios ambientais a partir da definição de padrões da estrutura que permitem a vida nas cidades incorporando medidas de preservação e conservação dos recursos naturais e culturais, de forma que, ao atender aos anseios sociais do presente "garanta a perpetuação dos recursos renováveis, possibilitando a perenidade ambiental e usos futuros" (RIBEIRO, 2010, p. 38).

Assim, a partir desse conceito de planejamento urbano ecológico, o qual incorpora a sustentabilidade como espinha dorsal, torna-se importante reconhecer a paisagem como um marco histórico em estado incessante de transformação, resultantes de suas interações naturais ou decorrentes da ação humana que pode agir de forma a garantir o equilíbrio dos ecossistemas, ajustando e ampliando as condições de absorção e recuperação dos espaços naturais, buscando garantir os ciclos vitais de cada ambiente.

\section{DESENHO URBANO: UM NOVO ENFOQUE PARA OS ESPAÇOS LIVRES PÚBLICOS}

A diversidade de espaços naturais é talvez a maior riqueza da humanidade. Os elementos que compõem a natureza, os corpos d água, montanhas, vegetação, dentre outros, constituem-se em recursos valiosos e valorosos para a qualidade ambiental dos espaços urbanizados, considerando sua função de equilíbrio entre o assentamento urbano e o meio natural. Nesse sentido, a qualidade do projeto a ser alcançado está relacionada às condições de equilíbrio, assim como da força potencial em conjugar a natureza diversa dos elementos existentes no local à serem estabelecidos no processo de intervenção.

No âmbito da questão, os processos de intervenção decorrentes do planejamento urbano ecológico, são orientados por princípios ou parâmetros, que se constituem em referências inseridas em um contexto de individualidade e singularidades, onde torna-se possível "explorar, em várias combinações, o que, em um determinado período da história e em um 
determinado lugar, será capaz de responder às necessidades ecológicas do meio físico e cultural da sociedade do lugar" (RIBEIRO, 2010, p.39).

Ao longo das últimas décadas, uma diversidade gigantesca de problemas voltados às questões ambientais tem sido apontadas com mais frequência em áreas urbanas, desse modo "os estudos relacionados com a qualidade do ambiente urbano podem contribuir para inovar os métodos de planejamento", por meio da elaboração de políticas públicas aptas em realizar adequações inteligentes, requalificando o uso e a ocupação do solo nas cidades, ao adotar soluções menos impactantes ao meio ambiente, e melhorar a qualidade de vida da população, que necessita de um ambiente ecologicamente equilibrado (AMORIM, 1993).

Miana (2010), ao tratar dessa problemática, enfatiza que a melhoria da qualidade ambiental das cidades também pode surgir de um aproveitamento adequado dos espaços disponíveis, com o desenvolvimento de uma nova morfologia configurativa.

\footnotetext{
Oportunidades de melhoria da qualidade ambiental nas cidades também surgem em vazios urbanos e áreas da periferia, onde pode ser desenvolvida uma nova morfologia configurativa, com o suporte de novas tecnologias, além de avançar altos níveis de sustentabilidade ambiental urbana. Nestes casos, a meta de densidade é determinada e limitada pelos requisitos e critérios relacionados às questões de qualidade ambiental, com acesso ao sol, qualidade do ar, conforto do pedestre, desempenho energético das edificações e potencial de geração de energia na área das edificações. (MIANA, 2010, p. 34).
}

Por esse ângulo, à contribuição do desenho urbano fundamentado em base sustentáveis, pode se constituir em um divisor de águas, ao promover a melhoria do espaço e por consequência, a melhoria da qualidade de vida. Com essa finalidade muitos são os componentes naturais que a natureza proporciona, dentre eles, a vegetação em toda sua diversidade, assim como a água desempenham funções primordiais na manutenção de microclimas, ao colaborar para a minimização dos efeitos nocivos das fontes de poluição, ajuda no equilíbrio dos ciclos hidrológicos, além de contribuir para a formação de uma referência estética do lugar.

Os padrões de infraestrutura, de sistemas viários, de parcelamento de solo, dentre outras tipologias presentes nas cidades, colaboram para existência de superfícies enormes impermeabilizadas, com desdobramentos desagradáveis e destrutivos, como "o aquecimento resultante da superexposição à radiação solar, as enchentes e os assoreamentos pós chuvas intensas". Frente a essas questões, surge como alternativa a implantação da infraestrutura verde, tendo em vista suas potencialidades, pois podem "propiciar consideráveis ganhos à saúde ambiental, sejam eles físicos, sociais, econômicos ou estéticos" (RIBEIRO, 2010, p39).

$\mathrm{Na}$ atualidade, o conceito do planejamento urbano ecológico, tem sido empregado em diversos trabalhos, dada sua importância para fundamentar novas políticas públicas, processos de gestão e desenho urbano, dentre outros. Ao viabilizarem técnica e economicamente a incorporação eficiente dos componentes ambientais ao meio urbano sua importância toma proporções surpreendentes. Além da riqueza estética e ambiental das alamedas, bulevares, parques e jardins, para serem aplicados nos complexos sistemas de drenagem urbana, o 
princípio de criação de uma estrutura ecológica ou de infraestrutura verde, como os corredores verdes urbanos aliado a otimização eficiente de controle de águas pluviais, e ainda, realizar o reflorestamento de encostas, arborização das vias pública, captação, reúso, infiltração das águas da chuva para reabastecimento do lençol freático - estas são apenas algumas práticas de baixo impacto e valores mínimos, que através de uma composição adequada de seus elementos poderão contribuir satisfatoriamente para um projeto de cidade onde os recursos naturais e físicos convivam em equilíbrio, trilhando o caminho da sustentabilidade.

Neste contexto, Ribeiro (2010) reconhece a importância do planejamento ecológico urbano ao incorporar os princípios da Infraestrutura Verde, notadamente por adotar quatro procedimentos para a definição do desenho urbano, dentre os quais,

- Reconhecer e delimitar a estrutura ecológica da Paisagem Urbana - dada pelas condições biofísicas e de biodiversidade do território, compostos por: Parques Lineares ou Corredores Verdes ao longo dos cursos d'água e seus fundos de vale; alagados; matas nativas; áreas íngremes ou muito frágeis; cumeeiras ou topos de morros; e áreas de solos férteis;

- Adotar um sistema complementar de Drenagem Urbana-com os princípios naturais de escoamento, purificação e armazenagem das águas pluviais, projetados na malha urbana como forma de minimizar os efeitos das corredeiras, lavagens, assoreamentos, ravinas e voçorocas que vem afetando nossas cidades, diminuindo de forma significativa os custos da estrutura tradicional das obras de arte, com resultados ecológicos, econômicos, estéticos e educacionais de grande importância na construção da sustentabilidade urbana;

- Planejar a mobilidade como elemento intrínseco da acessibilidade urbana de maneira que, ao definir as vias públicas que dão caráter ao desenho da malha urbana, o faça com atenção às distintas formas de locomoção;

- Planejar, implantar e manter a Floresta Urbana em rede formada pelo conjunto das áreas vegetadas livres urbanas, públicas e privadas, naturais ou construídas. (RIBEIRO, 2010, p. 137).

As normas propostas acima possui como fundamento a estrutura ecológica no ambiente dos espaços urbanizados, o que permite revisar o planejamento urbano a partir de outra lógica, considerando as unidades espaciais ou ambientes da cidade no sentido de desempenharem funções múltiplas: conectar fragmentos de vegetação, conduzir águas com segurança; oferecer melhorias microclimáticas; preservar as águas subterrâneas simultaneamente aos novos usos urbanos de habitação, trabalho, educação, lazer e suas demandas de transportes e abastecimento; e ainda atender, às tradicionais demandas de melhorias ambientais, de recreação e estética (RIBEIRO, 2010).

Para finalizar, a compreensão das áreas vegetadas como componente da infraestrutura verde urbana, emerge como técnica inovadora voltada à estruturação dos espaços naturais a serem regeneradas e integradas ao meio físico através do processo de planejamento e desenho das cidades enquanto possibilidades que acenam em busca de cidades mais justas e humanas e sobretudo, mais belas. 


\section{CONSIDERAÇÕES FINAIS}

As graves questões que afetam uma vivência saudável em diversas cidades do país, procuram evidenciar a urgência de intervenções governamentais que comtemplem novos paradigmas de planejamento e gestão das cidades.

Esse despertar acena um recomeço, onde se reconhece a relevância de integrar os espaços naturais aos espaços urbanizados, como alternativa aos processos de planejamento que almejam condições de equilíbrio entre os elementos naturais e a cidade que se produz continuamente.

Nesse sentido, a contribuição do desenho urbano fundamentado em bases sustentáveis, pode se constituir em um divisor de águas, ao promover a melhoria do espaço, e por consequência a melhoria da qualidade de vida.

$\mathrm{Na}$ atualidade, muitos estudos e pesquisas têm sido realizados, buscando aprofundar o conceito do planejamento urbano ecológico, considerando sua importância para fundamentar novas políticas públicas, processos de gestão e desenho urbano, dentre outros. Ao viabilizarem técnica e economicamente a incorporação eficiente dos componentes ambientais ao meio urbano sua importância toma proporções surpreendentes.

Com esse enfoque, as contribuições do desenho urbano ao possibilitarem a criação, ampliação e a melhoria das áreas verdes, intenciona implantar uma nova cultura no tratamento das questões urbanas ambientais, sobretudo aquelas voltadas ao enfrentamento dos problemas relacionados ao abandono, a ocupação irregular, ao uso e ocupação indevida dos espaços livres públicos, tornando o problema em oportunidade, tendo por fundamento os princípios e instrumentos metodológicos da infraestrutura verde, os quais poderão ser incorporados ao processo de planejamento na busca de soluções para a diversidade de demandas que assolam as cidades na contemporeneidade.

\section{REFERENCIAL}

AB`SÁBER, A. N.. Os domínios da natureza no Brasil: potencialidades. São Paulo: Ateliê Editorial, 2003.

Geomorfologia do Sítio Urbano de São Paulo. Edição Fac-Similar-50 anos. SãoPaulo: Ateliê Editorial., 2007.

ACSELRAD, H.. A duração das cidades - Sustentabilidade e risco nas Políticas Urbanas. Ed. PB\&A, 2001.

AMORIM, M. C. de C.T.. Análise ambiental e qualidade de vida na cidade de Presidente Prudente/SP. Dissertação (Mestrado em Geografia), Faculdade de Ciências e Tecnologia, Universidade Estadual Paulista, Presidente Prudente, 1993. 


\section{Revista Nacional de}

Caracterização das áreas verdes em Presidente Prudente/SP. In: SPOSITO, M. E. B. (org).

Textos e contextos para a leitura geográfica de uma cidade média (p. 37-52). Presidente Prudente, 2001.

LEFF, E.. Educação Ambiental e Desenvolvimento Sustentável. In: Verde Cotidiano: o meio ambiente em discussão. REIGOTA, M. (org.) - Rio de Janeiro: DP\&A., 1999.

. Saber Ambiental: sustentabilidade, racionalidade, complexidade, poder. Tradução de ORTH. L. M. E., Título original: Saber Ambiental: sustentabilidad, racionalidad, complejidad, poder. Petrópolis, RJ, Vozes, 2001.

HOUGH, M.. Natureza e cidade. Barcelona: Editorial Gustavo Gili S. A. 1998.

McHARG, I. L.. Design with nature. New York: American Museum of Natural History. Reeditado, 2000.

Proyectar con la Naturaleza. Gustavo Gili. Barelona, 2000.

MIANA, A. C.. Adensamento e forma Urbana: inserção de parâmetros ambientais no processo de projeto. Tese (Doutorado- Área de Concentração: Tecnologia da Arquitetura), FAUUSP. São Paulo, 2010.

PEllegrino, P. R. M.. Pode-se planejar a paisagem? In: Paisagem e Ambiente: ensaios São Paulo. Faculdade de Arquitetura e Urbanismo, n.13, dez. p.159 e180, 2000.

PELLEGRINO, P. R. M. et al.Paisagem da borda: uma estratégia para condução das águas, da biodiversidade e das pessoas. In: COSTA, L. M. S. A.(org). Rios e paisagens urbanas em cidades brasileiras. Rio de Janeiro: Viana\&Mosley; Editora PROURB, p. 57 e 76, 2006.

RIBEIRO, M. E. J.. Infraestrutura verde, uma estratégia de conexão entre pessoas e lugares: por um planejamento ecológico para Goiânia. Goiânia, 2010. 